\title{
Ballistic ejecta and eruption condition of the vulcanian explosion of Shinmoedake volcano, Kyushu, Japan on 1 February, 2011
}

\author{
Fukashi Maeno $^{1}$, Setsuya Nakada $^{1}$, Masashi Nagai ${ }^{2}$, and Tomofumi Kozono ${ }^{2}$ \\ ${ }^{1}$ Earthquake Research Institute, The University of Tokyo, 1-1-1, Yayoi, Bunkyo-ku, Tokyo 113-0032, Japan \\ ${ }^{2}$ National Research Institute for Earth Science and Disaster Prevention, 3-1, Tennodai, Tsukuba, Ibaraki 305-0006, Japan
}

(Received October 30, 2012; Revised February 21, 2013; Accepted March 9, 2013; Online published July 8, 2013)

\begin{abstract}
The physical condition of the 1 February, 2011, vulcanian explosion at Shinmoedake volcano, Japan, is estimated based on the size of impact craters created by ballistic ejecta, using a ballistic trajectory model and a scaling law for impact crater formation. The initial velocity, impact velocity and mass of ejecta were estimated at $240-290 \mathrm{~m} / \mathrm{s}, 140 \pm 20 \mathrm{~m} / \mathrm{s}$ and 1-3 ton, respectively. The gas mass fraction at the source was calculated to be $0.04-0.1$, using the initial velocity and a theoretical model of vulcanian explosion. This gas mass fraction is higher than the petrologically estimated value for pre-eruptive magma. Low-angle jets from the explosion and the estimated depth and size of a pressurized gas region suggest a shallow source inside the lava dome. The observation and results imply that segregation and accumulation of gas in a shallow conduit played a role in an increase of excess pressure immediately below the dome surface, prior to the vulcanian explosion.
\end{abstract}

Key words: Ballistic ejecta, impact crater, lava dome, vulcanian, Shinmoedake.

\section{Introduction}

A transient volcanic explosion is one of the typical eruption styles of andesitic volcanoes. It is characterized by explosions separated by intervals of minutes to days, and a violent nature with an instantaneous release of pressurized gas and solid/molten materials (e.g., Morrissey and Mastin, 2000). This eruption style, called Vulcanian, occurs as a consequence of magma ascent in a conduit and a gas-rich accumulation region at the top of the magma column (Self et al., 1979; Wilson, 1980). If pathways of gas to the surface are efficiently sealed by a coherent rock, gas pressure may increase to a point at which the sealing rock fails catastrophically, so that the solid/molten materials and gas are violently expelled in a transient explosion (Self et al., 1979; Wilson, 1980). In certain cases, a lava dome may act as a cap, and its failure may trigger transient explosions (e.g., Galeras volcano, Stix et al., 1997; Soufriere Hills volcano, Robertson et al., 1998; Novarupta volcano, Adams et al., 2006). Velocities of ejected materials may become supersonic in the surrounding atmosphere, as evidenced by the observation of shock waves (e.g., Nairn, 1976). The intensity, duration, and course of vulcanian-type explosions are varied, and the transitional behaviors from/to subplinian and strombolian eruptions are occasionally observed. A discrete, short-lived explosion like a cannon and a relatively-long, sustained explosion like a fire hose are probably two end-member types of vulcanian explosions (McBirney, 1973).

The determination of the initial physical condition, such

Copyright (c) The Society of Geomagnetism and Earth, Planetary and Space Sciences (SGEPSS); The Seismological Society of Japan; The Volcanological Society of Japan; The Geodetic Society of Japan; The Japanese Society for Planetary Sciences; TERRAPUB.

doi:10.5047/eps.2013.03.004 as the initial velocity and ejection angle of materials, is important to constrain the mechanism and process of explosion and to assess resultant hazards. Modeling studies of this type of eruption furnish a relationship between the velocity with which blocks are expelled from an explosion site, and pressure in the trapped gas that produces the explosion (Minakami, 1942; Wilson, 1980; Fagents and Wilson, 1993; Woods, 1995). However, it is not easy to determine the eruption condition from direct observations (Nairn and Self, 1978; Steinberg and Babenko, 1978; Druitt et al., 2002; Formenti et al., 2003). In certain cases, geological and petrological evidence for explosions offer constraints on this condition (e.g., Stix et al., 1997; Robertson et al., 1998; Adams et al., 2006).

Shinmoedake volcano is one of the active andesitic volcanoes in the Kirishima mountain range, Kyushu, Japan (Fig. 1). A series of explosion events, accompanying subplinian, vulcanian and dome-building stages, occurred at the volcano between January and May in 2011 (Nakada et al., 2013). In this paper, the initial condition of ballistic ejecta expelled from the vulcanian explosion at a growing andesitic lava dome on Shinmoedake volcano on 1 February, 2011, is estimated, based on the sizes of impact craters created by ballistic ejecta. In this estimation, we use a ballistic trajectory model (Mastin, 2008) and a scaling law for impact crater formation (Housen et al., 1983; Holsapple, 1993). The source condition is constrained using a vulcanian explosion model by Fagents and Wilson (1993). This combined approach, and the results, will be useful for understanding the process of vulcanian explosions and related hazards. 


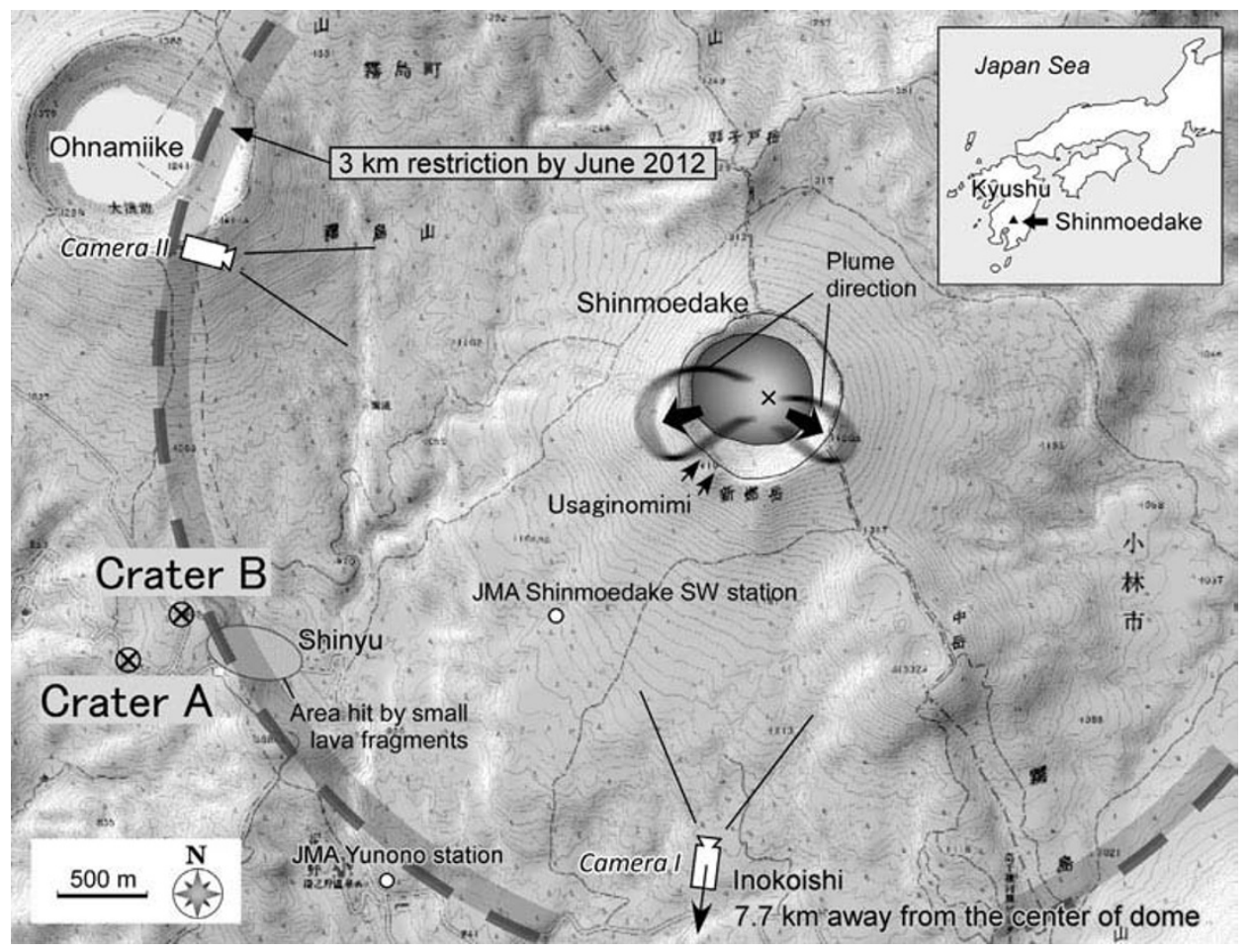

Fig. 1. Location map of the impact craters created by the vulcanian explosion of Shinmoedake at 07:54 on 1 February, 2011, lava dome and stations. Source location is determined by an aerial photograph taken by the Japan Meteorological Agency (JMA). Plume directions are indicated by black arrows, determined based on photographs taken by Camera I at Inokoishi and Camera II at Ohnamiike (see Fig. 2). Inset figure indicates the location of Shinmoedake volcano, southern Kyushu, Japan.

\section{Outline of the Vulcanian Explosion on 1 Febru- ary, 2011}

The Shinmoedake eruption in 2011 began with small precursory phreatomagmatic explosions on 19 January, followed by successive subplinian explosions during 26-27 January. During the subplinian stage, the column height of each explosion reached 6-7 km above the summit crater (Maeno et al., 2012; Shimbori and Fukui, 2012). After this stage, a lava dome began to grow upward at the center of the summit crater beginning 28 January. The dome was initially a small black-colored pile of diameter $\sim 30 \mathrm{~m}$, and then it grew to fill the summit crater (Nakada et al., 2013). In two days, the dome diameter reached about $500 \mathrm{~m}$ (Fig. 1). Steam rose vigorously from the top of the dome, and lava wrinkles strongly developed on its surface.

At 7:54 am on 1 February, 2011, there was a strong vulcanian explosion on top of the dome (Fig. 1). It was the first and largest of a series of transient explosions that continued over the next two months. Initially, a shock wave was observed. Then explosion clouds (jets at the beginning) started to rise up and were directed toward the west and east at an angle $20-40^{\circ}$ (Figs. 1 and 2) but within a few tens of seconds, the column grew vertically and ultimately formed a mushroom-shaped column. Plume development was observed by two remotely-operated cameras. One camera was located at Inokoishi (observed by the Japan Meteorological Agency, JMA), $7.7 \mathrm{~km}$ from the dome (Camera I in Fig. 1), and the other was located at Ohnamiike (observed by the Aira-Isa Regional Promotion Bureau, Kagoshima Prefecture), $3 \mathrm{~km}$ west of the Shinmoedake summit (Camera II in Fig. 1). Based on images from these cameras, the direction of plume development was roughly determined using fixed points (the location of a white steam plume and peaks called Usaginomimi; Figs. 1 and 2).

Numerous ballistic ejecta were expelled from the summit crater through the expanding explosion cloud. The explosion cloud reached the rim of the summit crater $(\sim 300 \mathrm{~m})$ in a few seconds. Finer materials were entrained into the rising plume. The plume height reached $2 \mathrm{~km}$ above a vent based on visual observation by JMA, while Shimbori and Fukui (2012) reported that the plume height reached $7 \mathrm{~km}$ above sea level based on Doppler radar observation. The plume then moved toward the southeast. Pyroclastic flows were not observed. The maximum amplitude of seismicity (3767 $\mu \mathrm{m} / \mathrm{s}$ ) was recorded at the Shinmoedake Southwest station, $1.7 \mathrm{~km}$ from the summit crater, and maximum air pressure $(458.4 \mathrm{~Pa})$ was measured at the Yunono station, $3 \mathrm{~km}$ southwest of the crater. The amplitudes of seismicity were the largest in the historical record of Shinmoedake eruptions (Japan Meteorological Agency, 2011). In the city of Kobayashi, over $10 \mathrm{~km}$ from the crater, roofs and windows of buildings were partially destroyed by small fragments of lava transported by the plume. In areas at the southern foot of the volcano, windows were broken by the shock wave. In some places to the southwest where ballistic ejecta and their fragments were landed, fires were started. Tephra distribution was unknown; hence tephra volume is not constrained, but probably is on the order of $10^{4} \mathrm{~m}^{3}$ based on a comparison to tephra data our group obtained for similar-scale vulcanian explosions during February to March 2011 (Unpublished data of Earthquake Research Institute).

In the same morning after the vulcanian explosion, the 

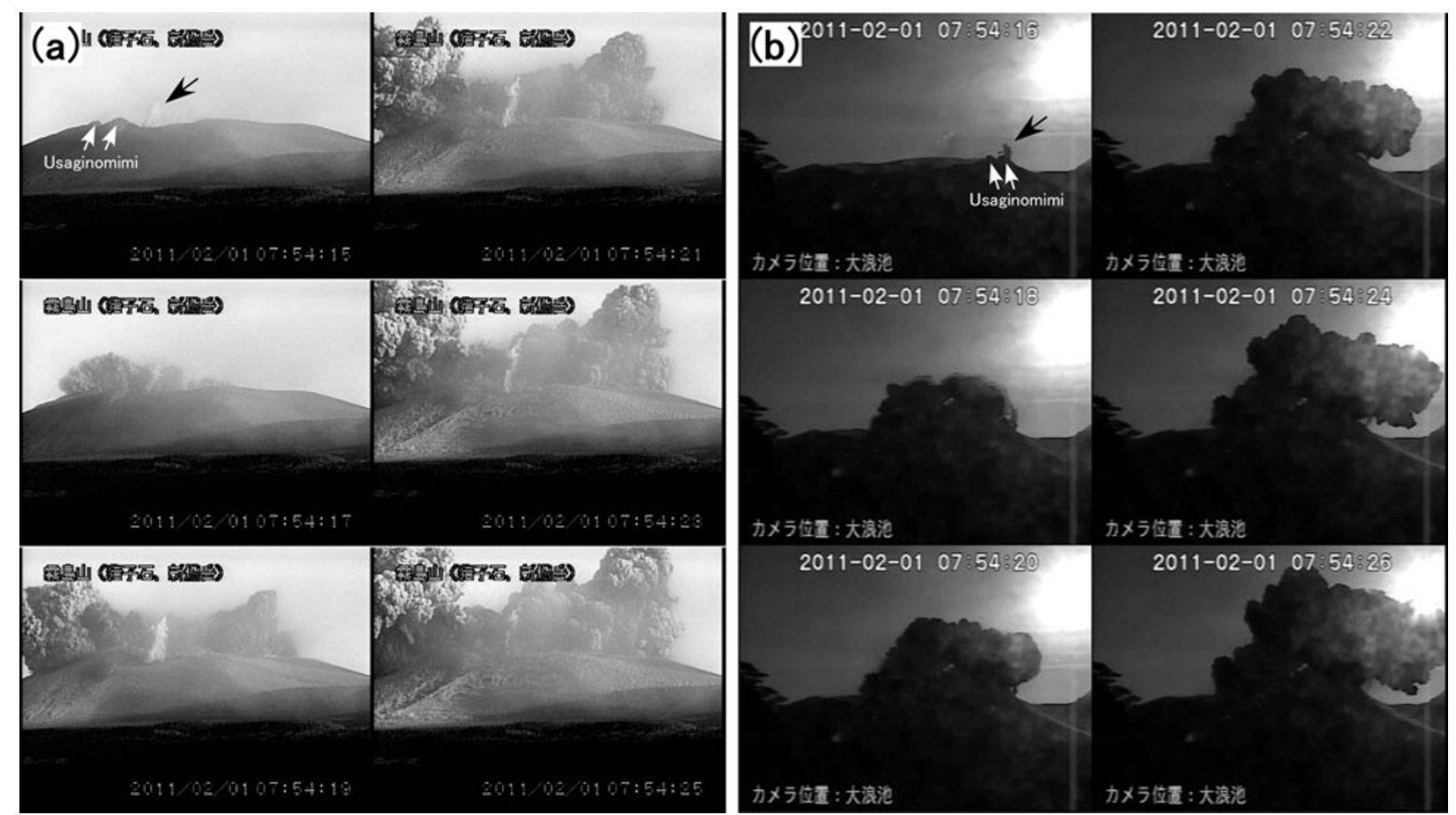

Fig. 2. Snapshots of plume development of vulcanian explosion of Shinmoedake on 1 February, 2011. (a) Photographs taken by the JMA from Inokoishi, $7.7 \mathrm{~km}$ south of the dome center (Camera I in Fig. 1), at 2-s intervals. (b) Photos taken by Aira-Isa Regional Promotion Bureau (Kagoshima Prefecture) from Ohnamiike, $3 \mathrm{~km}$ west of dome center (Camera II in Fig. 1), at 2-s intervals. Black arrow in the first frame of each figure indicates white steam plume rising from the crater rim. Two white arrows indicate peaks called Usaginomimi at the southern rim of the crater.

lava dome diameter was measured at about $500 \mathrm{~m}$ by a JMA airborne survey. This size was nearly the same as that on 31 January. The dome height was slightly reduced because the explosion destroyed its surface. Although the change of dome height was not precisely measured, it seemed very small compared to the thickness of the lava dome. The dome center was covered by blocky lava, but lava wrinkles at the outer part of the dome were still observed. The observation indicates that the explosion site was confined to the dome center, approximately within $250 \mathrm{~m}$ in diameter (half the size of the dome). The Geospatial Information Authority of Japan (2011) estimated the altitude of the top of the lava dome to be $1360 \mathrm{~m}$, based on Daichi Phased Array type L-band Synthetic Aperture Radar (PALSAR) intensity images on the same day after the explosion. The dome growth then slowed and almost ceased the next day. Based on these observations, we assumed that ballistic ejecta were launched from the lava dome center at the altitude of $1360 \mathrm{~m}$. The thickness of the lava dome at the explosion site was estimated to be about $130 \mathrm{~m}$, based on topographic data of pre- and post-explosion.

\section{Impact Craters Produced by Ballistic Ejecta}

During plume development of the vulcanian explosion on 1 February, numerous ballistic ejecta were expelled toward the southwest flank of Shinmoedake volcano. We studied two of the largest ballistic ejecta, found in the Shinyu area at the southwest foot of the volcano (Figs. 1, 3 and 4). They were the largest of all the erupted materials, except for ejecta in inaccessible areas near the summit crater. The JMA reported that these ejecta landed on this area immediately after the explosion and caused fires. The distances of
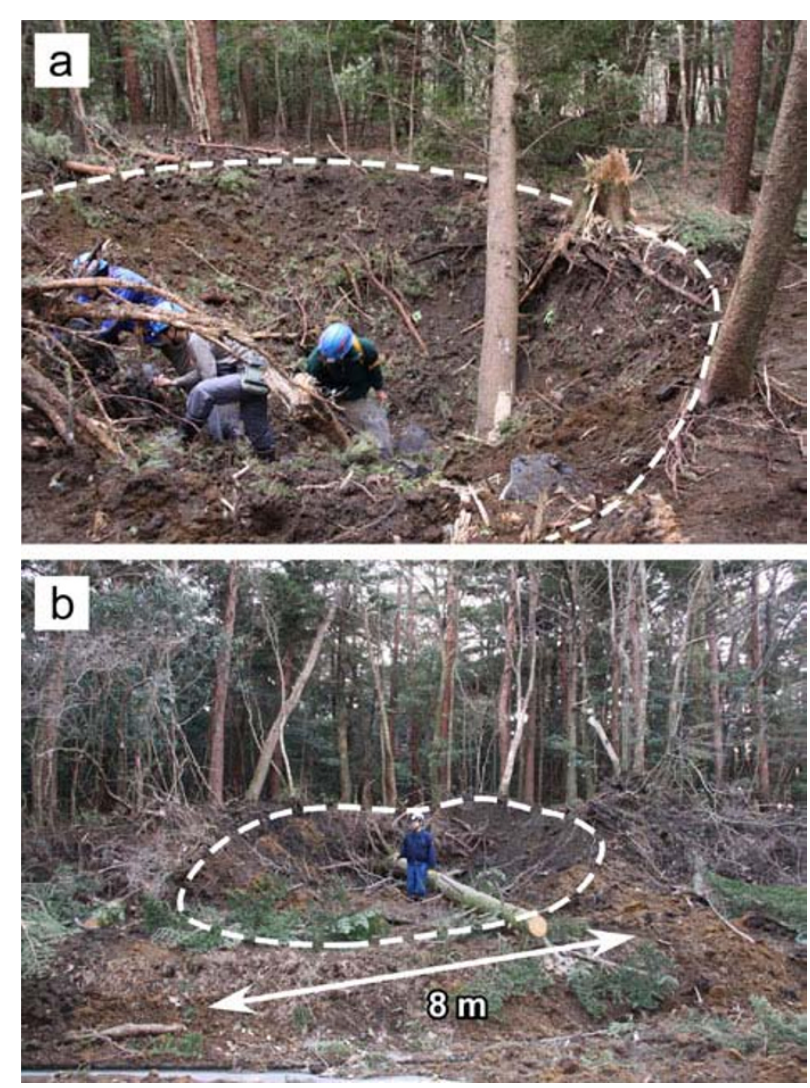

Fig. 3. Overview of impact craters at (a) location A, and (b) location B. Fragments of lava and wood are scattered around the craters. 

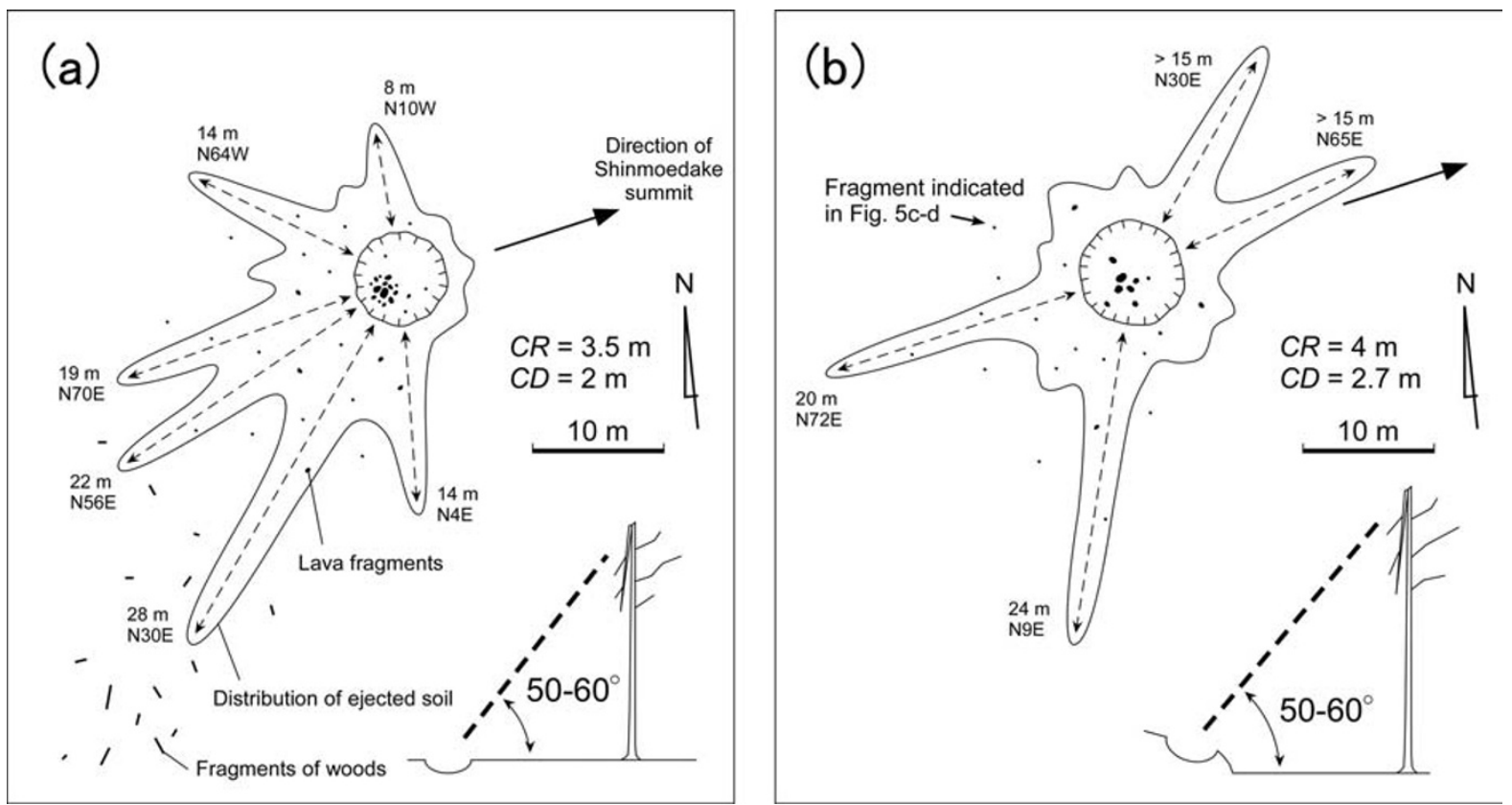

Fig. 4. Schematic illustrations of impact craters at location A (a), and location B (b). $C R$ : crater radius, $C D$ : crater depth.
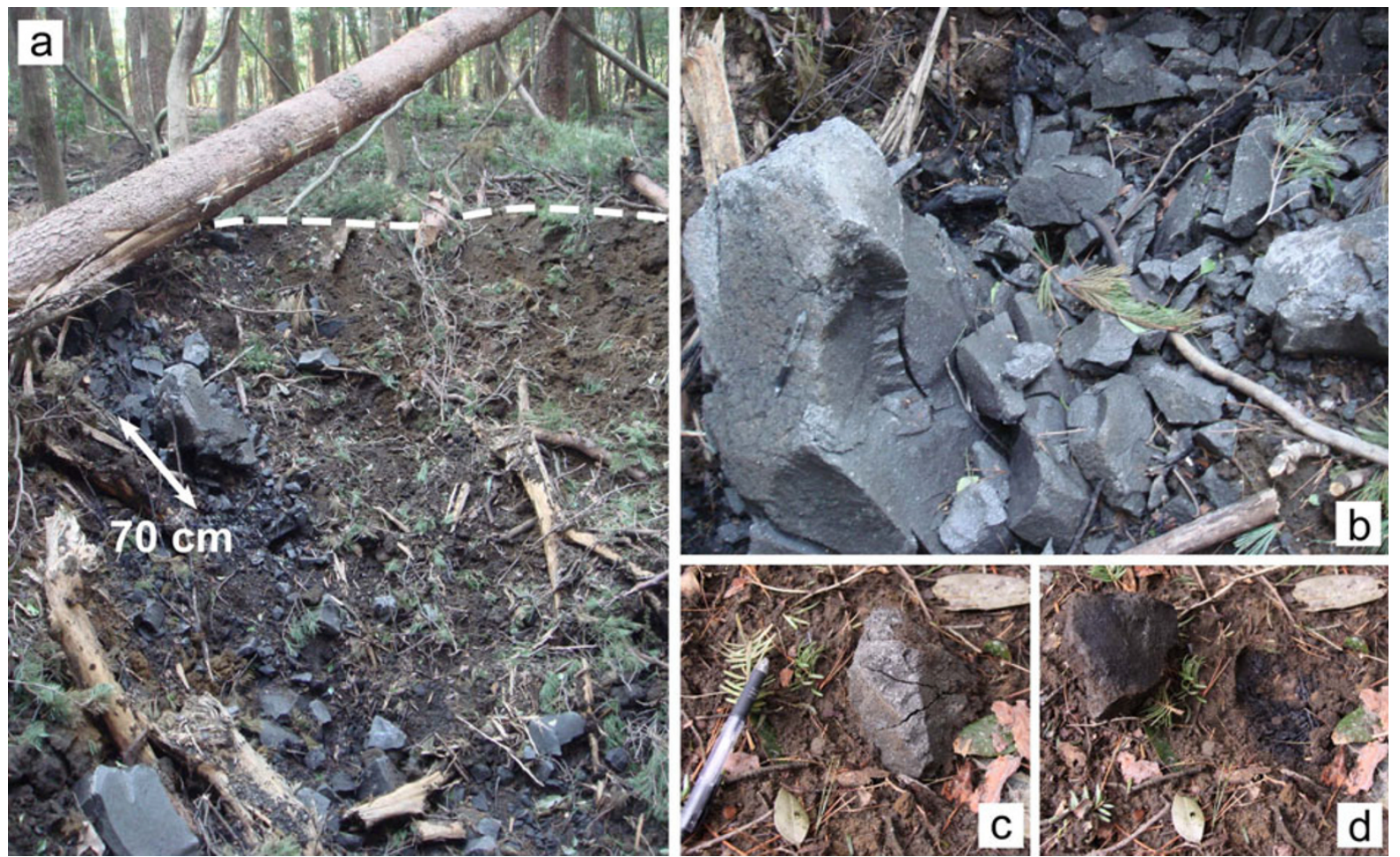

Fig. 5. (a) Interior of the impact crater at location A. The material filling the crater is a mixture of fragments of lava, wood and soil. (b) Magnification of shattered andesitic lava inside the crater A. (c) Fragment of lava, and (d) underlying leaves burned outside the crater (location B).

locations A and B (Fig. 1) from the dome center are about $3400 \mathrm{~m}$ and $3100 \mathrm{~m}$, respectively, with corresponding altitudes 945 and $963 \mathrm{~m}$ above sea level. Two large ballistic ejecta produced impact craters of radius $3.5 \mathrm{~m}$ at location $\mathrm{A}$, and $4 \mathrm{~m}$ at location B (Figs. 3 and 4). Lava fragments were scattered inside and outside the craters (Fig. 5(a), (b)), and some had underlying burned grasses (Fig. 5(c), (d)). Soil ejected from the impact crater was radially distributed, and wood fragments were also present (Fig. 4). Near both craters $\mathrm{A}$ and $\mathrm{B}$, the topmost few meters of trees were broken in the direction from which the ejecta came. Based on the height of the broken trees, the impact angle of ballistic ejecta was estimated to be $50-60^{\circ}$. Geological data of impact craters are listed in Table 1. The maximum lava block size at location A was about $70 \mathrm{~cm}$ along the long axis. However, its original size is believed to be larger than observed, because many lava fragments were scattered around the impact craters. Ballistic ejecta were probably shattered 
Table 1. Characteristics of impact craters produced by ballistic ejecta.

\begin{tabular}{lcc}
\hline Location & A & B \\
Distance $(\mathrm{m})$ & 3400 & 3100 \\
Elevation $(\mathrm{m})$ & 945 & 963 \\
Crater radius $(\mathrm{m})$ & 3.5 & 4 \\
Crater depth $(\mathrm{m})$ & 2.0 & 2.7 \\
Impact angle $\left({ }^{\circ}\right)$ & $50-60$ & $50-60$ \\
\hline
\end{tabular}

during impact, and cratering and lava fragments were produced (Fig. 5(b)). The original size of ballistic ejecta at location $\mathrm{B}$ is unknown.

Ballistic blocks were dense but have a few bubble textures, and there was no evidence of delayed vesiculation such as bread crust surfaces (Fig. 5(a)). This suggests that ballistic ejecta found in this area originated from solid lava that would seal pressurized gas beneath the dome but were still at a high temperature, so they caused fires and burned grass when they emplaced.

\section{Petrological Characteristics of Ballistic Ejecta}

The chemical composition of lava is andesite with 57.9 wt.\% of $\mathrm{SiO}_{2}$. The lava contains 30 vol.\% of phenocrysts (plagioclase, orthopyroxene, clinopyroxene and Fe-Ti oxide). Detailed petrological features of erupted materials from this explosion are described by Suzuki et al. (2013a). They suggest that the andesite was produced by syneruptive magma mixing before the explosion, and that the magma temperature was $960-980^{\circ} \mathrm{C}$ based on phenocryst compositions and thermodynamic calculations. The temperature inside the lava dome is unknown. We therefore assumed that the gas temperature was almost the same as the magma temperature $\left(970^{\circ} \mathrm{C}\right)$ or much lower $\left(770^{\circ} \mathrm{C}\right)$ in the calculation of the gas/mass fraction at the time of the explosion (Subsection 5.4). The water content of the melt in the conduit magma is uncertain, but less than $3 \mathrm{wt} . \%$ is plausible. This value is estimated from a phase equilibrium relationship in a storage condition of pre-eruptive magma (at 125 $\mathrm{MPa}$ ) and $\mathrm{H}_{2} \mathrm{O}$ analyses of melt inclusions, as discussed in Suzuki et al. (2013a). The density of lava blocks expelled from the dome surface is uncertain. Hence, we assumed this to be $2100-2400 \mathrm{~kg} / \mathrm{m}^{3}$. The minimum value of this range is a one measured by Y. Suzuki (personal comm.).

\section{Estimation of Eruption Conditions}

Our intent is to estimate the physical parameters characterizing the explosion and cratering processes, and to constrain the initial physical conditions of the vulcanian explosion at 7:54 on 1 February. The definition of the physical parameters is shown in Fig. 6. First, a relationship between the initial conditions (velocity, $v_{i}$; ejection angle, $\theta_{i}$; mass, $m_{i}$ ) of ballistic ejecta and the cratering conditions (distance, $D$; impact angle, $\theta_{f}$; impact velocity, $v_{f}$ ) was determined using the Eject! program (Mastin, 2008). This enabled calculation of the launch conditions, based on a mathematical model for ballistic trajectories. Second, using a scaling law describing the formation of impact craters (Housen et al., 1983; Holsapple, 1993), a relationship between the impact condition (mass and velocity) of ballistic ejecta and
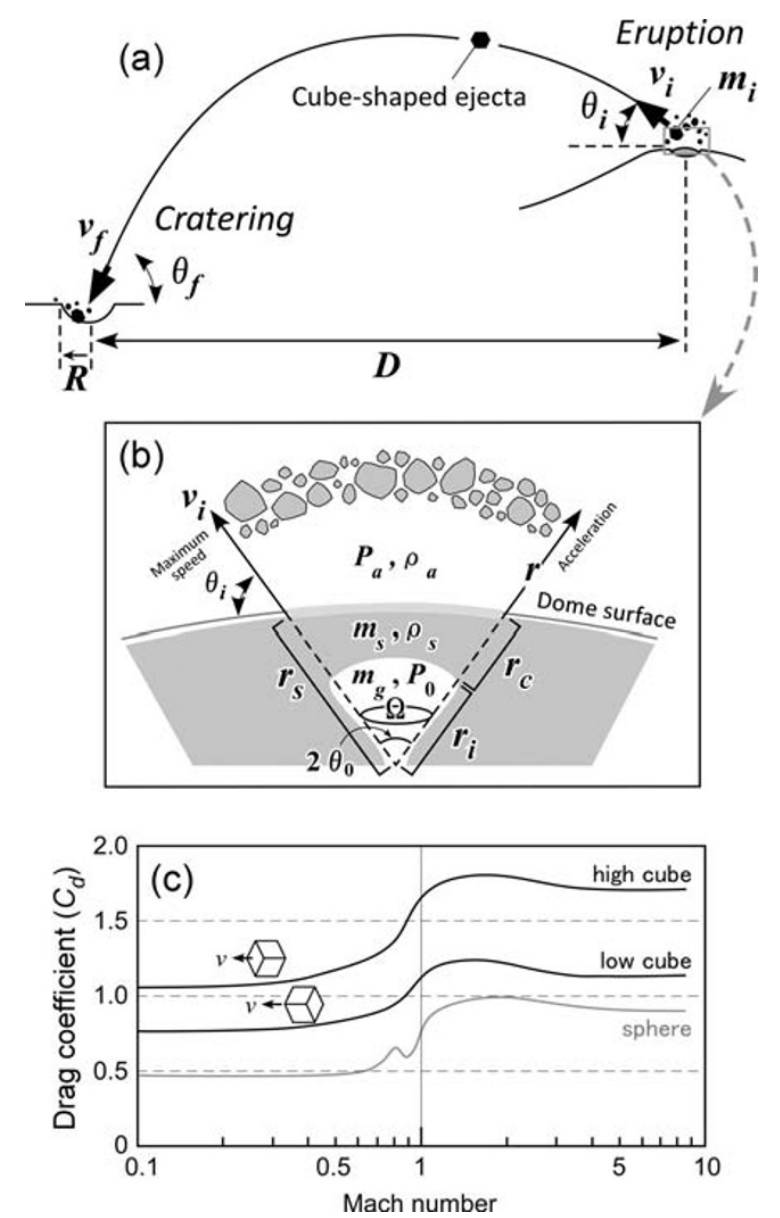

Fig. 6. (a) Definition of the physical parameters, characterizing the launch and cratering processes, also used in the calculations. $v_{i}$, initial ejection velocity; $\theta_{i}$, ejection angle; $m_{i}$, mass of ballistic ejecta; $D$, distance; $\theta_{f}$, impact angle; $v_{f}$, impact velocity; $R$, radius of the impact crater. (b) $P_{0}$, initial (explosion) pressure; $P_{a}$, atmospheric pressure; $m_{s}$, mass of solid material; $m_{g}$, mass of gas; $\rho_{a}$, the density of ambient air; $\rho_{s}$, the density of solid material at source and $r$, the distance that solid material has reached, are used in the Fagents and Wilson (1993) model. The dimension of a conical-shaped gas region is characterized by $r_{i}$, the radius of the conical region; $r_{s}$, the radius of the conical region plus the solid carapace; $r_{c}$, the thickness of the carapace; $\Omega$, solid angle of cone; $2 \theta_{0}$, apex angle. (c) Drag coefficients, $C_{d}$, varying with Mach number for two extreme cases for cubic shape blocks (high- and low-cube). For a high cube, one face is perpendicular to the flow direction, while a low-cube is oriented with a corner at the leading edge. The drag coefficient for a sphere (gray line) is also shown as a reference. Modified from Mastin (2008)

the crater size $(R)$ was established. Based on these results and the impact crater size, the initial condition of ballistic ejecta was estimated. Third, applying a theoretical model of vulcanian explosion (Fagents and Wilson, 1993) and using the estimated initial velocity, the mass ratio of gas $\left(m_{g}\right)$ to solid material $\left(m_{s}\right)$ on the dome surface was calculated (Fig. 6(b)).

\subsection{Calculation of trajectories of ballistic ejecta}

Lava blocks in flight are subjected to forces of drag against the atmosphere, and of gravity. Physical parameters and governing equations used in the trajectory model are shown in Appendix A. One of the key parameters is the size of ejecta, but the original size of ballistic ejecta that we found in the Shinyu area (Fig. 1) is unknown, because of 
Table 2. Parameters used in the calculations of ballistic trajectories.

\begin{tabular}{lrl}
\hline Atmospheric condition & & \\
Temperature at sea level & 3.2 & ${ }^{\circ} \mathrm{C}$ \\
Thermal lapse rate & 6.6 & ${ }^{\circ} \mathrm{C} / \mathrm{km}$ \\
Speed of tailwind* & -2 & $\mathrm{~m} / \mathrm{s}$ \\
\hline Initial condition & & \\
Diameter of cubic-shaped block & $0.5 \sim 1.1$ & $\mathrm{~m}$ \\
Density of block & 2100,2400 & $\mathrm{~kg} / \mathrm{m}^{3}$ \\
Initial velocity & $200 \sim 400$ & $\mathrm{~m} / \mathrm{s}$ \\
Ejection angle & $10 \sim 70$ & $\circ$ \\
Extent of zone of reduced drag & 300 & $\mathrm{~m}$ \\
Elevation of takeoff point & 1360 & $\mathrm{~m}($ a.s.1.) \\
Elevation of landing point & 945 & $\mathrm{~m}($ a.s.l.) \\
\hline
\end{tabular}

*An averaged windspeed component at a direction of ballistic trajectories $\left(250^{\circ}\right.$ clockwise from the north), calculated from wind profile data of JMA $\left(12 \mathrm{~m} / \mathrm{s}\right.$ at $1048 \mathrm{~m}$ above sea level with a direction of $316^{\circ}$, and $9 \mathrm{~m} / \mathrm{s}$ at $1504 \mathrm{~m}$ above sea level with a direction of $344^{\circ}$.)

fragmentation during emplacement. The drag coefficients of ejecta, which depend on their shape, are assumed to have values of cubic-shaped blocks (Fig. 6(c)). There is a minimum value for a low cube, for which the vertex between faces is at its leading edge. There is a maximum value for a high cube, for which one face is oriented perpendicular to the direction of motion (Mastin, 2008). The extent of a zone of reduced drag, which is caused by a coincident plume, was assumed to be $300 \mathrm{~m}$ (nearly equal to the radius of the Shinmoedake summit crater) based on video images of the explosion cloud (Fig. 2). This value generally has a range of the order of 10 to $100 \mathrm{~m}$ (Mastin, 2008). In our calculation, a difference in this value produces a variation of only a few percent in distance and is less influential than other parameters such as initial velocity, weight and ejection angle. The atmospheric conditions in the calculation was based on JMA data (temperature and wind speed/direction profiles) for the Kagoshima area acquired at 9:00 on 1 February, 2011. Parameters used in the calculations of ballistic trajectories are listed in Table 2.

The relationship between the initial and impact conditions for the 1.2 ton cube-shaped ejecta is shown as an example in Fig. 7. Figure 7(a) shows the relationship between the distance $D$ and the impact angle $\theta_{f}$ for various launch conditions (initial velocity $v_{i}$ and ejection angles $\theta_{i}=10$ $70^{\circ}$ ), where the results for high-cube shape ejecta with a density of $2400 \mathrm{~kg} / \mathrm{m}^{3}$ (solid lines) and for low-cube shape ejecta with a density $2100 \mathrm{~kg} / \mathrm{m}^{3}$ (broken lines) are shown for each initial velocity. These results correspond to maximum and minimum distances for the various initial conditions we examined. The errors caused by the variation of density and drag coefficient are considered in the following analyses. Figure 7(b) shows the relationship between the distance $D$ and the impact velocity $v_{f}$ for various launch conditions (initial velocity $v_{i}$ and ejection angles $\theta_{i}=10$ $70^{\circ}$ ). The relationship was affected by density and the drag coefficient (compare solid and broken lines), as in Fig. 7(a). Generally, the impact velocity takes a minimum value at an ejection angle of about $20^{\circ}$ for each case. Results for different elevations (Location A, $945 \mathrm{~m}$, and B, $963 \mathrm{~m}$ ) produced only $<0.5 \%$ errors in flight distance, which are very small
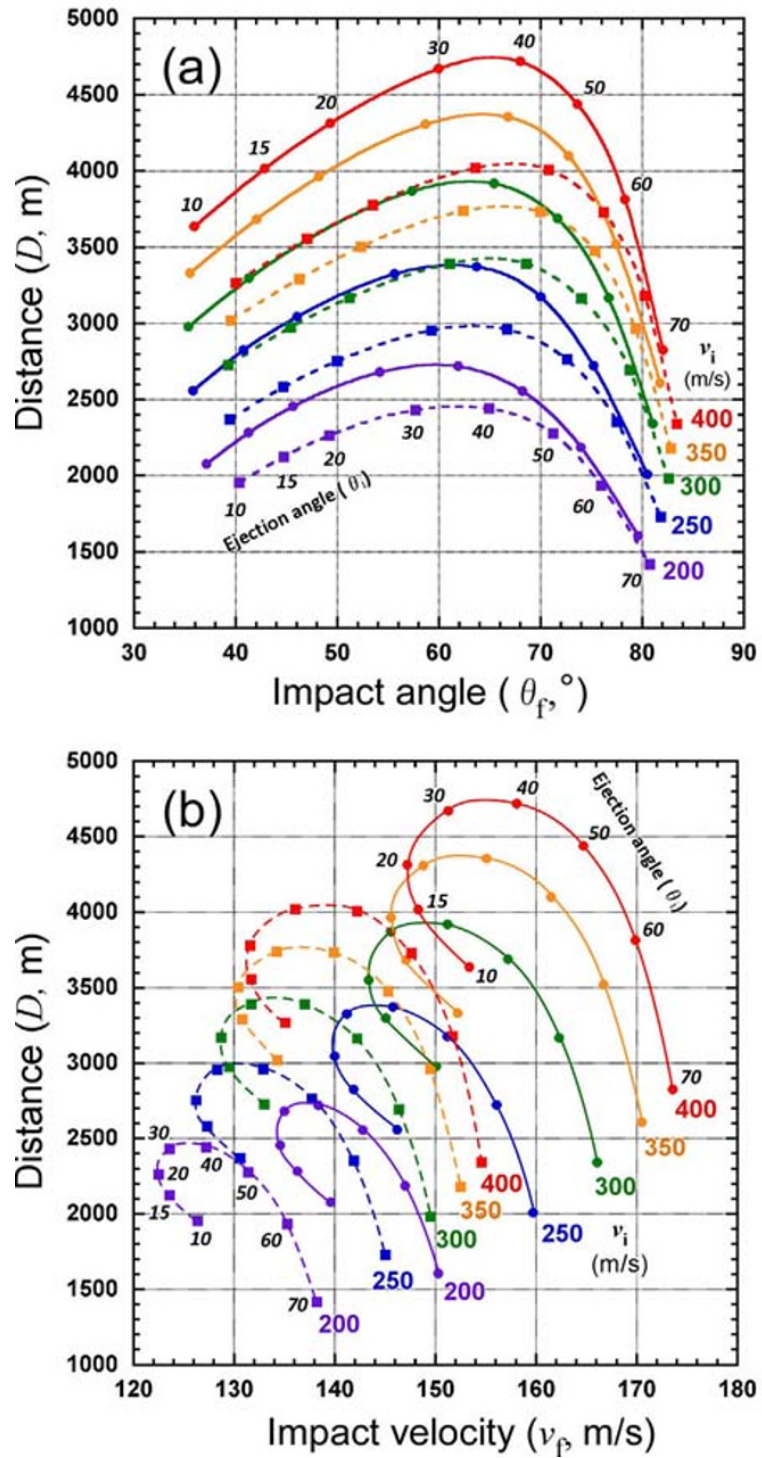

Fig. 7. Representative results of the calculation of ballistic trajectories using Eject! (Mastin, 2008). (a) Relationship between distance (D) and impact angle $\left(\theta_{f}\right)$ of ballistic ejecta $(m=1.2$ ton) for various launch conditions (initial velocity $v_{i}$ and ejection angles $\theta_{i}=10-70^{\circ}$ ). Solid lines indicate results for high-cubic ejecta with a density of 2400 $\mathrm{kg} / \mathrm{m}^{3}$. Broken lines indicate ones for low-cubic ejecta with a density of $2100 \mathrm{~kg} / \mathrm{m}^{3}$. Dots on lines indicate results for different ejection angles $\left(10-70^{\circ}\right)$. Some of them are numbered. (b) Relationship between distance $(D)$, and impact velocity $\left(v_{f}\right)$ for various launch conditions (initial velocity $v_{i}$ and ejection angles $\theta_{i}=10-70^{\circ}$ ) for 1.2 ton ejecta. Both figures are for a range of initial velocity, ejection angle and drag coefficients, for high and low cubic-shaped ejecta.

compared to errors from other factors such as the drag coefficients. Therefore, the same results were applied to both locations. Figure 7(a) also shows that the ejection angle could be approximately $20-40^{\circ}$ to satisfy the observed distances $\left(3100\right.$ and $3400 \mathrm{~m}$ ) and impact angles $\left(50-60^{\circ}\right)$. It is noteworthy that this ejection angle is consistent with the angle of explosion jets observed in an initial few seconds (Fig. 2). For other ejecta mass, results showed the same tendency as in the 1.2 ton case.

Figure 8 summarizes the relationship between distance and initial velocity for different ejecta mass $m_{i}$, and that between impact velocity and initial velocity for different 

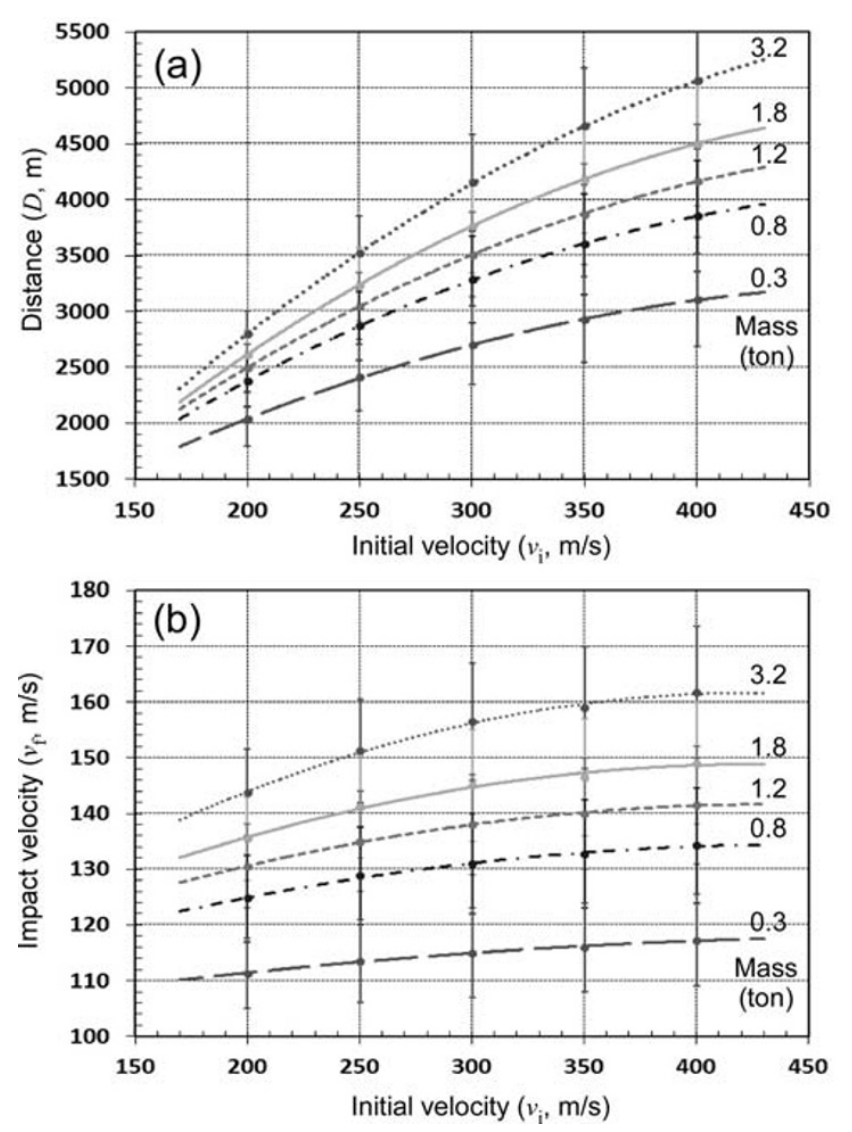

Fig. 8. (a) Relationship between the initial velocity $\left(v_{i}\right)$ and distance $(D)$ for different ejecta mass ( $m=0.3-3.2$ ton). (b) Relationship between impact velocity $\left(v_{f}\right)$ and initial velocity $\left(v_{i}\right)$ for different ejecta mass $(m)$. All calculations satisfy an impact angle $\left(\theta_{f}\right)$ of $50-60^{\circ}$. Solid circles indicate average values. Error bars include results for a range of impact angles and use drag coefficients for different ejecta shapes (high or low cubic).

ejecta mass. For example, to obtain a distance $D=3400 \mathrm{~m}$, $v_{i}$ must be $220-270 \mathrm{~m} / \mathrm{s}$ for 3.2 ton ejecta, $250-350 \mathrm{~m} / \mathrm{s}$ for 1.2 ton ejecta, and $>360 \mathrm{~m} / \mathrm{s}$ for 0.3 ton ejecta (Fig. 8(a)). Also to achieve $D=3400 \mathrm{~m}$, the impact velocity $v_{f}$ must be $138-164 \mathrm{~m} / \mathrm{s}$ for 3.2 ton ejecta, $126-150 \mathrm{~m} / \mathrm{s}$ for 1.2 ton ejecta, and $108-126 \mathrm{~m} / \mathrm{s}$ for 0.3 ton ejecta (Fig. 8(b)). Error bars are derived from ambiguity of impact angle $\left(50-60^{\circ}\right)$, density and drag coefficients, for low or high cubic shape of ejecta.

\subsection{Scaling law for impact crater formation}

The impact velocity $v_{f}$ of ballistic ejecta is correlated with impact crater size $r$, using a scaling law for crater formation (Housen et al., 1983; Holsapple, 1993; Housen and Holsapple, 2011). This scaling law has been applied to a wide range of cratering phenomena, such as water drops (on the order of $1 \mathrm{~m} / \mathrm{s}$ ) to meteorite impact (on the order of $1 \mathrm{~km} / \mathrm{s}$ ), when the impact angle $\theta_{f}$ is $>45^{\circ}$ (Housen and Holsapple, 2011). Impact processes are generally characterized by an inverse Froude number $g d /\left(2 v_{f}^{2}\right)$, where $g$ is the gravitational acceleration and $d$ is the impactor diameter, assuming a sphere (Holsapple, 1993). When the inverse Froude number is large and the effect of gravity is greater than that of the strength of basal materials, the impact process is categorized as the gravity regime (Holsapple, 1993).
The impact of ballistic ejecta caused by vulcanian explosions is generally thought to fall within this regime, because the inverse Froude number (on the order of $10^{-4}$ ) is almost equivalent to previously estimated values for cratering in this regime (Holsapple, 1993).

The scaling law of crater formation within the gravity regime (Housen and Holsapple, 2011) is written as:

$$
\Pi_{r}=K \Pi_{2}^{\alpha},
$$

where $\Pi_{r}$ and $\Pi_{2}$ are non-dimensional parameters as follows:

$$
\begin{aligned}
& \Pi_{r}=R\left(\rho_{b} / m_{i}\right)^{1 / 3}, \\
& \Pi_{2}=g d\left(2 v_{f}^{2}\right) .
\end{aligned}
$$

$K$ is constant and written in the following form:

$$
K=H_{1}\left(\rho_{b} / \rho_{i}\right)^{\beta}
$$

where $R$ is the impact crater radius, $\rho_{b}$ is the basal material density (here, $1500 \mathrm{~kg} / \mathrm{m}^{3}$ is assumed for soil), $m_{i}$ is the impactor mass, $\rho_{i}$ is the impactor density, and $\beta$ is the exponent and written as $(2+\mu-6 v) /[3(2+\mu)] . \quad v$ is a constant $(=0.4)$ that is independent of impact condition, and $\mu$ and $H_{1}$ are constants dependent on the porosity of basal materials and determined by laboratory experiments. For water or dense rock, $\mu=0.55$ was used. The power of $\alpha$ is $-\mu /(2+\mu)$. The basal material is soil, but appropriate laboratory data are lacking. Thus, we assumed $\mu=0.41$ as a minimum value determined for a dry granular material with porosity $40 \%$ (Housen and Holsapple, 2011), and $\mu=0.5$ as a maximum value for relatively wet granular material with less porosity. $H_{1}$ is 0.8 , which was ascertained by laboratory experiments using glass microspheres with $\mu=0.45$ (Housen and Holsapple, 2011). The relationship of impact velocity $v_{f}$ with mass $\left(m_{i}=0.3-3.2\right.$ ton) and impact crater size $(R)$ is shown in Fig. 9, where $\mu$ is assumed to be in the range $0.41-0.5$.

Considering the above relationship (Fig. 9), for example, to produce an impact crater of $3.5 \mathrm{~m}$ radius in soil with $\mu=0.41$, an impact velocity of $100 \mathrm{~m} / \mathrm{s}$ is required for 3.2 ton ejecta, $155 \mathrm{~m} / \mathrm{s}$ for 1.8 ton ejecta, and $>190 \mathrm{~m} / \mathrm{s}$ for less than 1.2 ton ejecta. It is important to note that for producing the same sized crater, heavier impactors require a smaller impact velocity, but lighter ones require a higher impact velocity. We neglected the effect of density difference (2100 and $2400 \mathrm{~kg} / \mathrm{m}^{3}$ ) because it was very small compared to errors from other factors ( $<2 \%$ error for impact velocity).

\subsection{Initial condition of ballistic ejecta}

Based on the results of trajectory calculations (Fig. 8), to simultaneously achieve impact angles $50-60^{\circ}$ and distance $3.4 \mathrm{~km}$ (location A), the impact velocity must be 138-164 $\mathrm{m} / \mathrm{s}$ for 3.2 ton ejecta, $126-150 \mathrm{~m} / \mathrm{s}$ for 1.2 ton, and $108-$ $126 \mathrm{~m} / \mathrm{s}$ for 0.3 ton. However, to produce an impact crater with $R=3.5 \mathrm{~m}$, the impact velocity must be $<100 \mathrm{~m} / \mathrm{s}$ for 3.2 ton and $>200 \mathrm{~m} / \mathrm{s}$ for 0.3 ton (Fig. 9). Ejecta of $0.8-2$ ton can satisfy the scaling relation for a $3.5-\mathrm{m}$ crater. For a 4-m crater at $3.1 \mathrm{~km}$ (location B), 1.2-3.2 ton ejecta can satisfy this relation.

Based on Figs. 8 and 9, possible ranges of initial velocities for each ballistic ejecta were determined (horizontal 


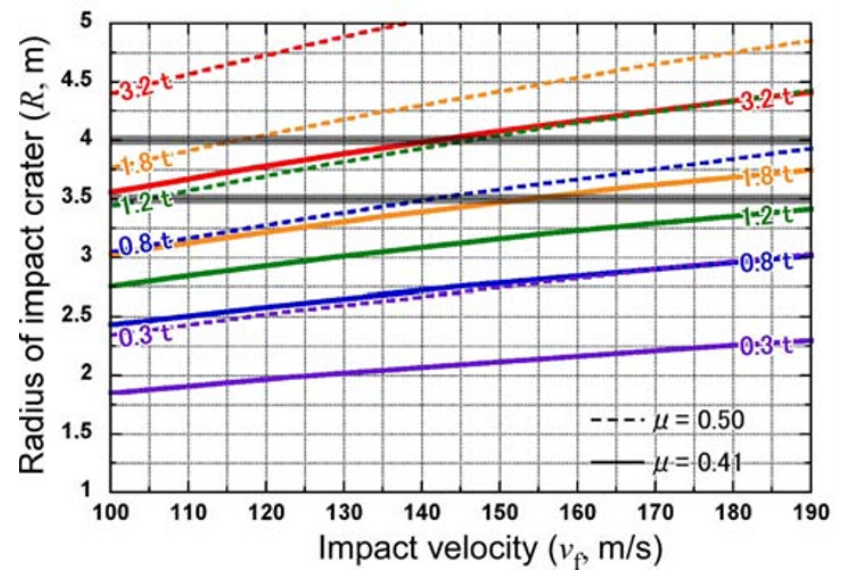

Fig. 9. Relationship between impact velocity $\left(v_{f}\right)$ and radius of the impact crater $(R)$ for different mass of ballistics $(m=0.3-3.2$ ton $)$ and different soil properties $(\mu)$. Solid lines are for $\mu=0.41$, broken lines for $\mu=0.5$.
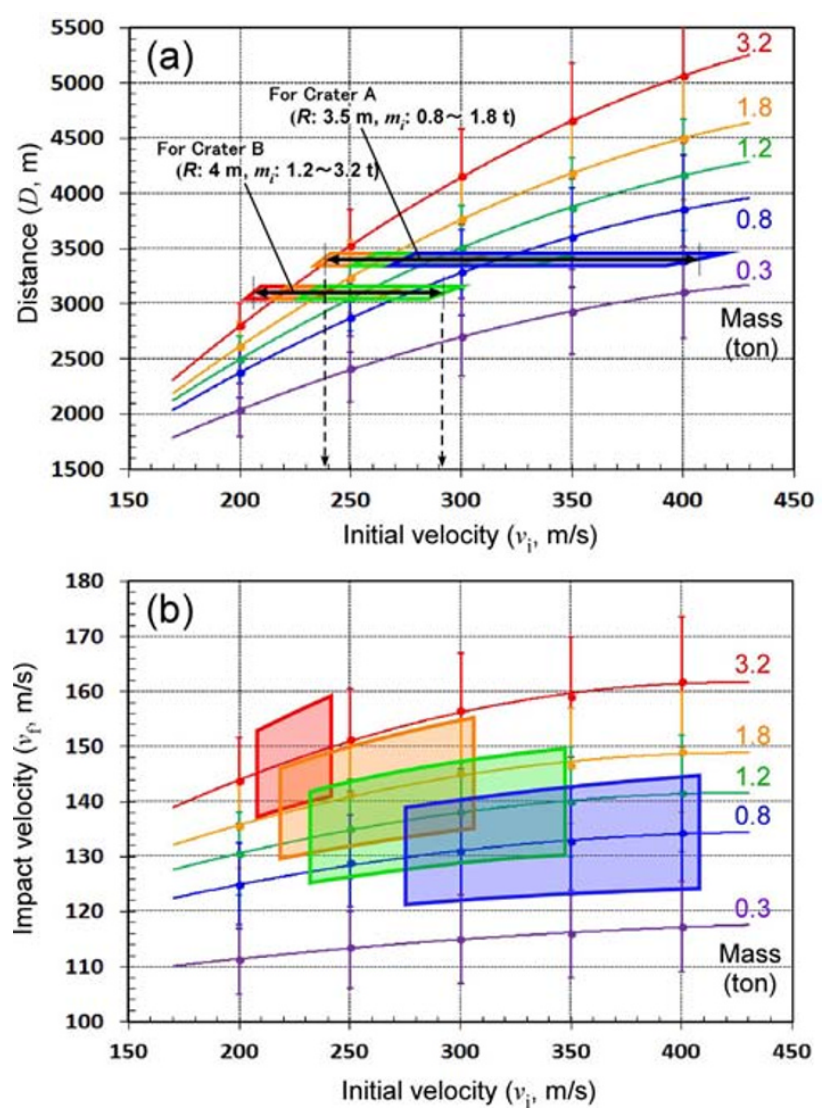

Fig. 10. Relationship between the initial velocity and distance for different ejecta mass. Shaded regions and horizontal arrows indicate possible ranges of initial velocities for each ballistic ejecta at two locations, which satisfy the impact condition as shown in Fig. 9. Vertical broken lines indicate the minimum and maximum values that two ballistic ejecta could have the same initial velocity. (b) Relationship between impact velocity $\left(v_{f}\right)$ and initial velocity $\left(v_{i}\right)$ for different ejecta mass $(m)$. Shaded regions indicate possible ranges of initial velocities for each ballistic ejecta to produce observed the impact craters.

arrows in Fig. 10(a)). Furthermore, considering that two ballistic ejecta could have the same initial velocity, the most plausible initial velocity is estimated to be about 240-290 $\mathrm{m} / \mathrm{s}$, as indicated by vertical broken lines in Fig. 10(a).
Shaded regions in Fig. 10(b) indicate possible ranges of impact velocity for every mass, which satisfy the distances 3100 and $3400 \mathrm{~m}$. Impact velocities for both locations are $120-160 \mathrm{~m} / \mathrm{s}$.

The distance $D$ that a ballistic block travels is related to the initial ejection velocity $v_{i}$. Moreover, the velocity is related to the amount and pressurization of gas driving the explosion via an equation of motion. Here, the physical condition prior to the vulcanian explosion was estimated, using the model of Fagents and Wilson (1993). This model takes, as its starting point, an amount of gas held at a pressure $\left(P_{0}\right)$ in a conical-shaped region capped by a solid material that, following sudden decompression, displaces and accelerates a dense slug of caprock plus a mass of atmospheric gas overlying the explosion site (Fig. 6(b)). As the caprock ruptures into fragments, individual blocks are launched into the atmosphere, moving at approximately the same speed. The equation of motion for the acceleration of the solid blocks plus air is written in the following form (Fagents and Wilson, 1993):

$$
\frac{d^{2} r}{d t^{2}}=\frac{3 r^{2}\left[P_{0}\left(r_{i} / r\right)^{3 \gamma}-P_{a}\right]}{\rho_{s}\left(r_{s}^{3}-r_{i}^{3}\right)+\rho_{a}\left[\left(r+r_{c}\right)^{3}-r_{s}^{3}\right]},
$$

and the mass ratio of gas to solid material $\left(m_{g} / m_{s}\right)$ can be written as:

$$
\frac{m_{g}}{m_{s}}=\frac{\rho_{g} r_{i}^{3}}{\rho_{s}\left(r_{s}^{3}-r_{i}^{3}\right)},
$$

where $r$ is the distance that the solid material has reached, $r_{i}$ is the radius of the conical region filled with gas at pressure $P_{0}, r_{s}$ is the radius of the conical region plus a solid carapace, $r_{c}\left(=r_{s}-r_{i}\right)$ is the thickness of the carapace, $\gamma$ is the specific heat capacity ratio, $P_{a}$ is the ambient atmospheric pressure, $\rho_{g}$ is the density of pressurized gas, $\rho_{a}$ is the density of ambient air, $\rho_{s}$ is the density of solid material which is the same as the impactor density, and $t$ is time.

If Eq. (5) is integrated twice, the maximum velocity of the expanding envelope, corresponding to the initial ejection velocity, $v_{i}$, in the trajectory model, is obtained. The implication is that the initial drag forces acting on the blocks are essentially zero, only becoming significant as the gas velocity decays. Fagents and Wilson (1993) showed that with allowance for this effect, pre-explosion gas pressures completely compatible with rock tensile strengths were predicted for a number of well-documented examples. Our approach is to infer the mass ratio of solid material $\left(m_{s}\right)$ to volatile concentrations $\left(m_{g}\right)$ responsible for the ejection velocity of ballistic ejecta, calculated with Mastin (2008) as discussed above. The vulcanian explosion would begin once the gas pressure $\left(P_{0}\right)$ exceeds that from the overlying dome mass, or when the cool outer dome material fails in a brittle manner. Although Fagents and Wilson (1993) modeled an explosion from a large pressurized gas cavity enclosed by a solid caprock, this approach can also be adapted to a system where gas and magma are intermixed (Robertson et al., 1998). In the following discussion, we focus only on the case where a large gas cavity exists.

\subsection{Gas/solid mass fraction and source condition}

Ballistic blocks with a few bubble textures suggest that the lava dome surface was degassed and solidified prior 
to disruption and ejection. The pre-explosion gas pressure $\left(P_{0}\right)$ would therefore have had to overcome a bulk lava strength consisting of the yield strength of the molten interior and the tensile strength of the solid exterior of the lava dome. For previously studied vulcanian explosions, it was demonstrated that explosion pressure is on the order of 1-10 MPa, entirely compatible with the expected range of tensile strengths of caprock materials (e.g., Nairn and Self, 1978; Self et al., 1979; Fagents and Wilson, 1993). Field examinations of hot dacitic lava blocks have indicated that their strengths may be low. These blocks were easily shattered by blows from a hammer (Mt. St. Helens, Mellors et al., 1988; Mt. Unzen, Sato et al., 1992). In fact, fragmented and shattered ballistic blocks that we surveyed also indicate that the strength of dome lava was very low (Fig. 5(b)). These lower strengths may be attributed to thermal stresses, trapped residual gas, or high strain caused by the presence of a large proportion of crystals (30 vol.\% in the Shinmoedake case, Suzuki et al., 2013a) within the viscous melt. It follows that caprock consisting of hot juvenile material should display similar failure properties. The strength of silicic magma is not well constrained, but is likely to be within 1-10 MPa (Romano et al., 1996) and may be reduced by the presence of crystals and bubbles caused by local stress amplification (Spieler et al., 2004). Thus, it may be argued that maximum tensile strength is on the order of $10 \mathrm{MPa}$. Given uncertainties in the bulk strength of the dome material, we therefore adopted a range
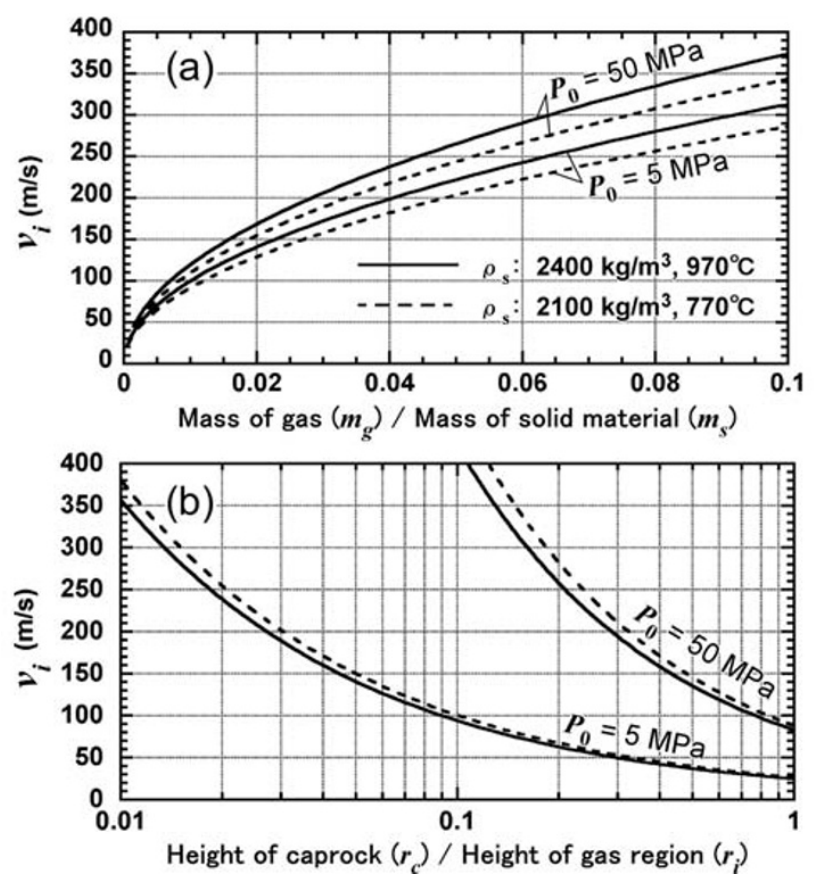

Fig. 11. Ejection velocity $v_{i}(\mathrm{~m} / \mathrm{s})$ as a function of confining pressure (5, $50 \mathrm{MPa})$ at the source, calculated using Fagents and Wilson (1993). (a) Relationship between the mass ratio of gas to solid material and the initial velocity of ballistic ejecta. (b) Relationship between ratio of caprock to gas region height and initial velocity $\left(v_{i}\right)$ of ballistic ejecta, assuming a large pressurized gas cavity enclosed by a solid caprock. Two extreme cases of initial conditions (solid lines for $2400 \mathrm{~kg} / \mathrm{m}^{3}$ and $970^{\circ} \mathrm{C}$, and broken lines for $2100 \mathrm{~kg} / \mathrm{m}^{3}$ and $770^{\circ} \mathrm{C}$ ) were examined for every confining pressure. of initial pressure $P_{0}=5-50 \mathrm{MPa}$. Although this choice of pressure is arbitrary, it allows us to bracket the range of plausible explosion pressures.

Applying a theoretical model of vulcanian explosion (Fagents and Wilson, 1993) and taking an initial velocity 240$290 \mathrm{~m} / \mathrm{s}$, the mass ratio of gas $\left(m_{g}\right)$ to solid material $\left(m_{s}\right)$ at the source is estimated to be $0.04-0.1$ for an initial pressure 5-50 MPa (Fig. 11(a)), where we assumed that the gas temperature is almost the same as the magma temperature $\left(970^{\circ} \mathrm{C}\right)$ or much lower $\left(770^{\circ} \mathrm{C}\right)$, and that the density of ejecta is 2100 or $2400 \mathrm{~kg} / \mathrm{m}^{3}$. In Fig. 11(a), results for two extreme cases are shown for each initial confining pressure.

A mass ratio of gas to solid material $\left(m_{g} / m_{s}\right)$ is estimated by Eqs. (5) and (6), if we assume a large pressurized gas cavity with height $r_{i}$ enclosed by a solid caprock with height $r_{c}\left(=r_{s}-r_{i}\right)$. For the same variation of gas temperature and ejecta density as in Fig. 11(a), the ratio of caprock height to gas region height is calculated to be approximately $0.02-0.2$ (Fig. 11(b)). In the calculations, we adopt results that the initial acceleration of ejecta occurred over a short distance (less than a few hundred meters), which lie on a range of error for estimation of the flight distance of ballistic ejecta.

\section{Discussion}

The initial velocity of ballistic ejecta was estimated to be $240-290 \mathrm{~m} / \mathrm{s}$. This value does not contradict previous studies of vulcanian-type explosions, in which initial velocities of ballistic ejecta were estimated to be $100-400 \mathrm{~m} / \mathrm{s}$ (e.g., Morrissey and Mastin, 2000; Parfitt and Wilson, 2008). For the Sakurajima volcano in Japan, those for representative vulcanian explosions in 1982-1987 were estimated to be $110-240 \mathrm{~m} / \mathrm{s}$, based on analyses of ballistic trajectories, and the explosion pressure was constrained to be 14-63 MPa (Iguchi et al., 1983; Ishihara, 1985, 1990). For the Soufriere Hills volcano, Montserrat, ballistic ejecta of the explosion on 17 September, 1996, was expelled with a velocity of 180 $\mathrm{m} / \mathrm{s}$ and an explosion pressure of $27.5 \mathrm{MPa}$ (Robertson et al., 1998). Druitt et al. (2002) and Formenti et al. (2003) estimated the exit velocities of jet accompanying ballistics at $<150 \mathrm{~m} / \mathrm{s}$ and the initial pressure at a few to $10 \mathrm{MPa}$ for other vulcanian explosions at the Soufriere Hills volcano. Our estimation of the initial velocity of ejecta for the Shinmoedake explosion is almost equivalent to the maximum case for the Sakurajima volcano and higher than examples from the Soufriere Hills volcano.

It is noteworthy that the initial velocity of ballistic ejecta is not correlated with eruption scale, such as erupted volume and plume height. For typical vulcanian explosions accompanying ballistic ejecta at the Soufriere Hills volcano, the plume height reached $>10 \mathrm{~km}$ above sea level, and the erupted volume was on the order of $10^{5} \sim 10^{6} \mathrm{~m}^{3}$ (Robertson et al., 1998; Druitt et al., 2002). On the other hand, for the vulcanian explosion at Shinmoedake on 1 February, 2011, the plume height was $\sim 7 \mathrm{~km}$ above sea level (based on Doppler radar observation, Shimbori and Fukui, 2012) and the erupted volume was probably on the order of $10^{4} \mathrm{~m}^{3}$. Explosion events in Soufriere Hills created large plumes sustained by a gas stream, and a large amount of vesicular magma was erupted from a deeper part of the conduit (a depth of 0.5-2 km or more; Druitt et al., 2002; 
Formenti et al., 2003). The explosion at Shinmoedake volcano was more violent, but with a smaller volume and lower plume height. Ejected material was probably derived from the lava dome itself. The difference between these explosion styles indicates two end-member types of vulcanian explosion (McBirney, 1973): 'cannon-like' (for Shinmoedake volcano) and 'gas-stream' (for Soufriere Hills volcano).

A noticeable observation for the explosion at Shinmoedake volcano was that the jet angle of the explosion was very low $\left(20-40^{\circ}\right)$ and directed toward the east and west (Fig. 2). This type of low-angle jet is likely to reflect the source depth. Ohba et al. (2002) studied the relationship between shapes of explosion clouds, explosion energies (J) and scaled depths that are defined as the explosion depth divided by the cube-root of the explosion energy $\left(\mathrm{m} / \mathrm{J}^{1 / 3}\right)$. In their experiments, funnel-shaped, low-angle jets were observed in shallow-depth explosions. Since cloud shapes were similar at the same scaled depths, they asserted that the scaling law is a good approximation for the shapes of explosion clouds. The scaling arguments for explosion phenomena are useful to constrain the source parameters, so that they were applied to some examples of volcanic explosions (e.g., Yokoo et al., 2005). Based on a comparison between the shape of the observed eruption cloud (Fig. 2) and the explosion experiments of Ohba et al. (2002), it is plausible that the vulcanian explosion source was at a very shallow depth, where the scaled depth is at least $<0.002 \mathrm{~m} / \mathrm{J}^{1 / 3}$.

Although it is not easy to determine the explosion energy precisely, taking the simplest approach that approximates a gas region with a pressure vessel, the explosion energy $E$ can be roughly estimated from the following Brode's equation (Baker et al., 1983):

$$
E=\left(\frac{P_{0}-P_{a}}{\gamma-1}\right) V
$$

where $V$ is the volume of a pressure vessel and is calculated from $V=1 / 3(\Omega) r_{i}^{3}$, assuming a conical-shaped gas region (Fig. 6(b)). $\Omega$ is the solid angle of the cone with an apex angle $2 \theta_{0}$, which is the area of a spherical cap on a unit sphere, so that $\Omega$ is written as $2 \pi\left(1-\cos \theta_{0}\right) . P_{a}$ is the ambient atmospheric pressure, and $\gamma$ is the specific heat capacity ratio. The relationship between explosion energy and $r_{s}$ and $r_{c}$ for various conditions can be calculated using Eq. (7). Results for $P_{0}=50 \mathrm{MPa}, r_{c} / r_{i}=0.2$ and for $P_{0}=5 \mathrm{MPa}, r_{c} / r_{i}=0.02$ are shown in Fig. 12(a) and 12(b), respectively, both of which satisfy the initial velocity of ballistic ejecta $(250-290 \mathrm{~m} / \mathrm{s})$ and correspond to two extreme cases of $r_{c} / r_{i}$ (Fig. 11(b)). In calculations, $\theta_{i}$ was set to be $20-40^{\circ}$, so that the apex angle $2 \theta_{0}$ is $100-140^{\circ}$. Even if we assume isentropic, or isothermal, expansion for a pressurized gas cavity, instead of using Eq. (7), the results are of the same order of explosion energy.

Although the explosion crater was not clearly observed at the dome surface, the dome height was slightly decreased and the dome center was covered by blocky lava due to the explosion. Our interpretation is that the area within a half of dome diameter ( $\sim 250 \mathrm{~m}$ in maximum) was destroyed and fragmented by the explosion and the depression was buried by fallback, because lava wrinkles were still well developed, except for the dome center. To further constrain
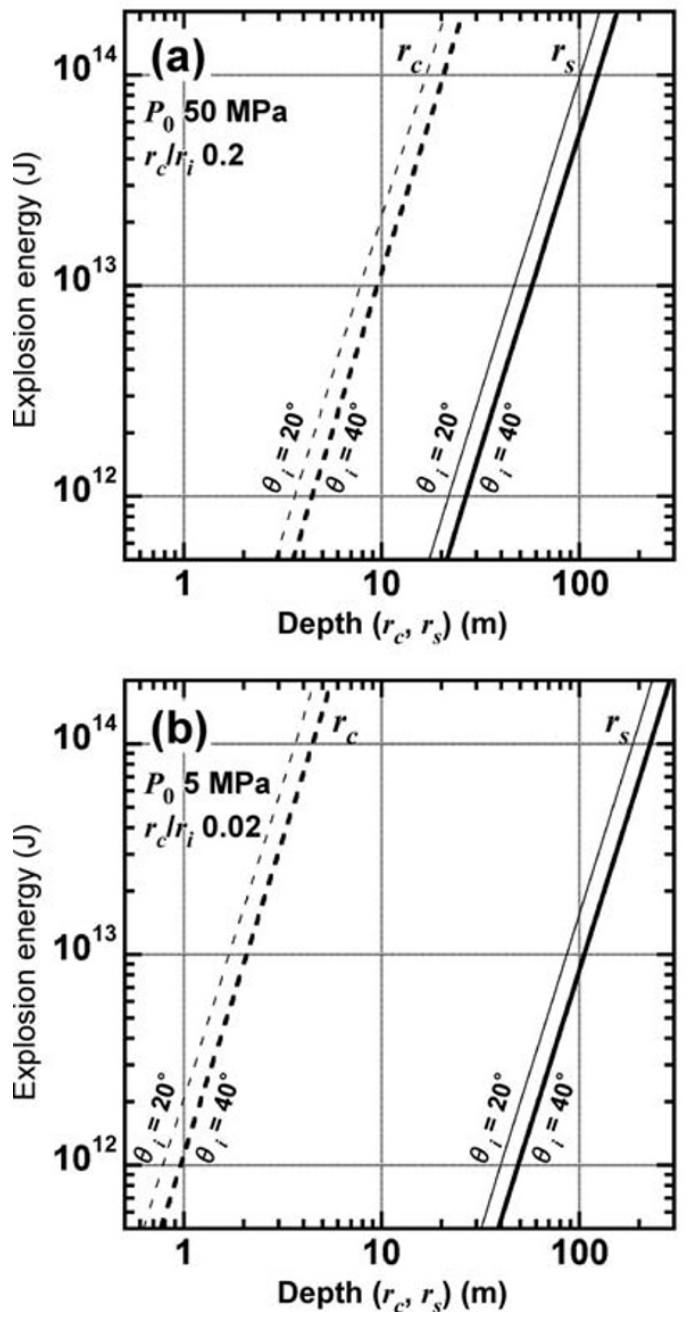

Fig. 12. Relationship between depth which characterizes the dimension of the conical-shaped gas region $\left(r_{c}\right.$ and $\left.r_{s}\right)$ and the explosion energy $E$ calculated from Brode's equation. (a) Results for the initial condition $P_{0}=50 \mathrm{MPa}$ and $r_{c} / r_{i}=0.2$. (b) Results for the initial condition $P_{0}=5 \mathrm{MPa}$ and $r_{c} / r_{i}=0.02$. Ejection angles $\theta_{i}$ were set to be 20 and $40^{\circ}$.

the source condition, we assume that the (hidden) explosion crater was in the area of blocky lava, and also that the explosion follows the scaling law describing the relationship between explosion energy $E$ and explosion crater size $D_{\text {exp }}$ (Goto et al., 2001; Ohba et al., 2002).

The scaling law is written as $\log D_{\exp }=0.32 \log E-$ 2.06. In order to produce the diameter of the explosion site $(<250 \mathrm{~m}), E$ should be $<8 \times 10^{13} \mathrm{~J}$. Moreover, according to the relationship between the scaled depth $\left(\mathrm{m} / \mathrm{J}^{1 / 3}\right)$ and the scaled distance of the ballistic ejecta $\left(\mathrm{m} / \mathrm{J}^{1 / 3}\right)$ found in field experiments (figure 4 in Yokoo et al., 2005), the maximum scaled distance should be $0.2-0.3 \mathrm{~m} / \mathrm{J}^{1 / 3}$ when the scaled depth is $<0.002 \mathrm{~m} / \mathrm{J}^{1 / 3}$, which corresponds to near-surface explosions. Based on this relationship, the explosion energy produced ballistic ejecta flying at least $3400 \mathrm{~m}$ is estimated to be $>1 \times 10^{12} \mathrm{~J}$. The estimated range of the explosion energy $\left(1 \times 10^{12}<E<8 \times 10^{13}\right)$ constrains the dimension of the conical-shaped gas region characterized by $r_{i}, r_{c}$ and $r_{s}$ through Eq. (7). The depth of the gas region top $r_{c}$ could be $4 \sim 20 \mathrm{~m}$ for $P_{0}=50 \mathrm{MPa}$ (Fig. 12(a)), or $1 \sim 4 \mathrm{~m}$ for 
$P_{0}=5 \mathrm{MPa}$ (Fig. 12(b)). These depths indicate that the pressurized gas region was in a very shallow level inside the lava dome with a thickness of approximately $130 \mathrm{~m}$.

In fact, the mechanism of the violent explosion at Shinmoedake volcano on 1 February, 2011 is still ambiguous, because tephra deposit (grain size variation, etc.) and petrological characteristics are not constrained enough. Nevertheless, the estimated physical condition provides information of the explosion source. The mass ratio of gas to solid material, 0.04-0.1, estimated in this study exceeds the volatile content of andesitic magma beneath the Shinmoedake volcano (approximately $0.03-0.04$ at $115 \mathrm{MPa}$ ) estimated from petrological analyses (Suzuki et al., 2013a). In fact, the volatile content could be less than 0.03 in a shallower conduit or lava dome. The discrepancy between the estimated mass ratio and the volatile content may be explained by vaporization of external water in porous country rocks in contact with the magma (e.g., Self et al., 1979), and/or by the concept that excess gas for driving the explosion is contributed by the degassing and crystallizing magma body (e.g., Stix et al., 1997; Druitt et al., 2002).

The idea of vaporization of external water is supported by the geological background that a shallow hydrothermal system is developed beneath the Kirishima Volcano Group (e.g., Kagiyama et al., 1996). This is also supported by the facts that most of the historical explosive activities in the Shinmoedake volcano is characterized by phreatic and phreatomagmatic eruptions (Imura and Kobayashi, 2001). Even for vulcanian explosions at the later stage of the 2011 event, magma-water interaction is suggested based on a microscopic analysis of ash particles (Suzuki et al., 2013b). However, this idea is questionable for the 1 February vulcanian explosion because it is likely that the shallow hydrothermal system had been mostly dried up during the subplinian and dome-building stages in January.

The vulcanian activity on 1 February, 2011, was the first explosive event of a series of transient explosions that continued over the next several months. The lava dome rapidly grew in the summit crater within a few days after subplinian explosions, so the overlying dome might efficiently seal a vent and prevent gas emission. Although there were some fumarolic activities on the dome, no open conduit or crater was observed on the dome surface before 1 February. Accumulation of gas inside the dome, or near the dome surface, might cause excess pressure. A system where gas and magma are intermixed is also possible for gas accumulation. With time, pressure eventually increased by further accumulation of gas and finally overcame the bulk strength of the lava dome, then catastrophically broke the dome surface. One of the plausible mechanisms of a pressurizing lava dome is the exsolution of magmatic volatiles from rapid microlite growth (e.g., Stix et al., 1997; Druitt et al., 2002). Even small amounts of crystallization ( $<20 \mathrm{vol} . \%)$ can produce overpressures of 5-20 MPa, which are sufficient to fracture rocks (Tait et al., 1989). Detailed petrological analyses of dome lava will be needed for further investigations of this scenario.

A vulcanian explosion from an unconfined, horizontal dome surface, as observed in Shinmoedake volcano, is probably common for andesitic volcanoes but has not been studied well. Further studies on the mechanism and dynamics of this type of vulcanian explosion will be interesting. They should be constrained based on geophysical observations such as seismic records and acoustic signals (shock waves), that we did not focus on in this study, as well as petrological studies on the vesicularity, crystallinity and volatile content of juvenile material which will be useful to constrain the physical condition of explosion. Determination of the initial physical condition, such as the initial velocity and ejection angle of materials, is important not only to constrain the mechanism and process of the explosion, but also to assess resultant hazards. Impacts of ballistic ejecta is one of the most hazardous phenomena in vulcanian explosions, as witnessed in recent eruptions at Colima volcano, Mexico (1999), Popocatepetl volcano, Mexico (2003), Asama volcano, Japan (2004), etc. The physical condition will contribute to the determination of a distribution of ballistic ejecta and their impacts around the volcano quantitatively. The combined approach using geological data of ballistic ejecta and modeling results will also enable making hazard zonation and establishing more sophisticated assessments of hazards.

\section{Conclusions}

Impact craters were created by ballistic ejecta during the vulcanian explosion of Shinmoedake volcano, on 1 February, 2011. Based on the size of impact craters and a ballistic trajectory model and scaling law for impact crater formation, the initial velocity and impact velocity of ballistic ejecta were estimated to be $240-290 \mathrm{~m} / \mathrm{s}$ and $140 \pm 20 \mathrm{~m} / \mathrm{s}$, respectively. The mass of ballistic ejecta was estimated to be $0.8-2$ ton for a location $3.4 \mathrm{~km}$ distant, and 1.2-3.2 ton at a location $3.1 \mathrm{~km}$ distant. The gas mass fraction at the source was calculated to be 4-10 wt.\%, using a theoretical model of vulcanian explosion. This fraction is larger than the petrologically-estimated value for pre-eruptive magma (0.03-0.04 at $115 \mathrm{MPa}$, Suzuki et al., 2013a). Assuming a large pressurized gas cavity enclosed by a solid caprock, the ratio of caprock height to gas region height was computed to be $0.02-0.2$. Low-angle jets of the vulcanian explosion and the estimated depth and size of the gas region indicate that the explosion occurred at a very shallow depth inside the lava dome. The observation and results imply that segregation and accumulation of gas in a shallow conduit played a role in increasing excess pressure prior to the vulcanian explosion.

Acknowledgments. We thank the JMA (Japan Meteorological Agency) and the city of Kirishima for a field survey in the Shinyu area. We are also grateful to the JMA and Kagoshima Prefecture for providing video images of the explosion of Shinmoedake volcano on 1 February, 2011. We are also grateful to Y. Suzuki for discussion about the petrological features of erupted magma, and to M. Ichihara for providing information on sequential photographs of the explosion. The manuscript was improved by insightful comments from two anonymous reviewers. This study was supported by a Grant-in-Aid for Scientific Research (No. 22900001) from MEXT, Japan.

\section{Appendix A. Physical Parameters and Governing Equations Used in Eject!}

This appendix briefly summarizes the physical param- 
eters and governing equations used in the Eject! model (Mastin, 2008). In this model, blocks in flight are subjected to forces $(F)$ of drag against the ambient air, and of gravity. The governing equations in the horizontal $(x)$ and vertical (z) directions are written as:

$$
\begin{aligned}
& \frac{d v_{x}}{d t}=\frac{F_{x}}{m_{i}}=\frac{-v_{x} \rho_{a} v A C_{d}}{2 m_{i}}, \\
& \frac{d v_{z}}{d t}=\frac{F_{z}}{m_{i}}=\frac{-v_{z} \rho_{a} v A C_{d}}{2 m_{i}}-g \frac{\rho_{i}-\rho_{a}}{\rho_{i}},
\end{aligned}
$$

where $\rho_{a}$ is the air density, $\rho_{i}$ is the density of the ballistic block (=impactor density), $A$ is the cross-sectional area of the block, $C_{d}$ is the drag coefficient on the block, $m_{i}$ is the mass of the block (impactor), $g$ is the gravitational acceleration, $v$ is the block's velocity and $t$ is time. The effect of a horizontal tailwind of velocity on block motion is introduced into $v_{x}$ and $v$ in both Eqs. (A.1) and (A.2). The impact angle and velocity are also calculated from these equations.

The air density $\left(\rho_{a}\right)$ varies with elevation and is recalculated at each point in the trajectory using the equation for a perfect gas. The density of the ballistic block $\left(\rho_{i}\right)$ is fixed as 2100 or $2400 \mathrm{~kg} / \mathrm{m}^{3}$ in this study. $A$ depends on the shape and mass (or density) of the block, $A=d^{2}$ (where $d$ is the length of a side) for high-cubes in which one face is perpendicular to the flow direction, and $\sqrt{3} d^{2}$ for low-cubes oriented with a corner at the leading edge. For a sphere, $(1 / 4) \pi d^{2}$ (where $d$ is diameter) is used. $C_{d}$ varies with two dimensionless parameters: Reynolds number $(R e)$ and Mach number $(M)$. Eject! calculates $\operatorname{Re}\left(=\rho_{a} v d / \eta\right)$ and $M(=v / c)$ and determines $C_{d}$ at each point in the trajectory, where $\eta$ is the air viscosity calculated taking an atmospheric temperature based on the empirical relation and $c$ is the sound speed in air.

\section{References}

Adams, N. K., B. F. Houghton, S. A. Fagents, and W. Hildreth, The transition from explosive to effusive eruptive regime: The example of the 1912 Novarupta eruption, Alaska, Geol. Soc. Am. Bull., 118, 620-634, doi:10.1130/B25768.1, 2006.

Baker, W. E., P. A. Cox, P. S. Westine, J. J. Kulesz, and R. A. Strehlow, Explosion Hazards and Evaluation, 807 p., Elsevier, Amsterdam, 1983.

Druitt, T. H., S. R. Young, B. Baptie, C. Bonadonna, E. S. Calder, A. B. Clarke, P. D. Cole, C. L. Harford, R. A. Herd, R. Luckett, G. Ryan, and B. Voight, Episodes of cyclic Vulcanian explosive activity with fountain collapse at Soufriere Hills Volcano, Montserrat, in The Eruption of Soufriere Hills Volcano, Montserrat, from 1995 to 1999, edited by T. H. Druitt and B. P. Kokelaar, Geol. Soc. London Mem., 21, 483-516, 2002.

Fagents, S. A. and L. Wilson, Explosive volcanic eruptions. VII. The ranges of pyroclasts ejected in transient volcanic eruptions, Geophys. J. Int., 113, 359-370, 1993.

Formenti, Y., T. H. Druitt, and K. Kelfoun, Characterisation of the 1997 Vulcanian explosions of Soufriere Hills volcano, Montserrat, by video analysis, Bull. Volcanol., 65, 587-605, 2003.

Geospatial Information Authority of Japan, Crustal deformations around Kirishima Volcano, Rep. Coord. Comm. Predict. Volcan. Erup., 108, 197-220, 2011.

Goto, A., H. Taniguchi, M. Yoshida, T. Ohba, and H. Oshima, Effects of explosion energy and depth to the formation of blast wave and crater: Field explosion experiment for the understanding of volcanic explosion, Geophys. Res. Lett., 28, 4287-4290, 2001.

Holsapple, K. A., The scaling of impact processing in planetary sciences, Ann. Rev. Earth Planet. Sci., 21, 333-373, 1993.

Housen, K. R. and K. A. Holsapple, Ejecta from impact craters, Icarus, 211, 856-875, 2011.
Housen, K. R., R. M. Schmidt, and K. A. Holsapple, Crater ejecta scaling laws: fundamental forms based on dimensional analysis, J. Geophys. Res., 88(B3), 2485-2499, 1983.

Iguchi, M., K. Ishihara, and K. Kamo, On ejection of velocity and pressure of volcanic explosion reduced from photo-trajectory of volcanic bombs, Ann. Disas. Prev. Res. Inst., Kyoto Univ., 26(B-1), 9-21, 1983 (in Japanese with English abstract).

Imura, R. and T. Kobayashi, Geological map of Kirishima volcano, Geological Survey of Japan, pp. 8, 2001 (in Japanese with English abstract).

Ishihara, K., Dynamical analysis of volcanic explosion, J. Geodyn., 3, 327349, 1985.

Ishihara, K., Pressure sources and induced ground deformation associated with explosive eruptions at an andesitic volcano: Sakurajima volcano, Japan, in Magma Transport and Storage, edited by M. P. Ryan, 335356, Wiley and Sons, New York, 1990.

Japan Meteorological Agency, Volcanic activity of Kirishima VolcanoFebruary, 2011-May, 2011-, Rep. Coord. Comm. Predict. Volcan. Erup., 109, 139-167, 2011.

Kagiyama, T., H. Utada, M. Uyeshima, F. Masutani, W. Kanda, Y. Tanaka, H. Masuda, H. Murakami, I. Shiozaki, M. Ichiki, T. Yukutake, T. Mogi, K. Amita, N. Oshiman, and M. Mishina, Resistivity structure of the central and the southeastern part of Kirishima volcanoes, Bull. Volcanol. Soc. Jpn., 41, 215-225, 1996 (in Japanese with English abstract).

Maeno, F., M. Nagai, S. Nakada, R. E. Burden, S. Engwell, Y. Suzuki, and T. Kaneko, Constraining tephra dispersion and deposition from cyclic subplinian explosions at Shinmoedake volcano, Kyushu, Japan, 2011, Japan Geoscience Union Meeting, SVC50-07, 2012.

Mastin, L. G., A simple calculator of ballistic trajectories for blocks ejected during volcanic eruptions, version 1.4, U.S. Geol. Sur. Open File Rep., 01-45, 2008.

McBirney, A. R., Factors governing the intensity of andesitic eruptions, Bull. Volcanol., 37, 443-453, 1973.

Mellors, R. A., R. B. Waitt, and D. A. Swanson, Generation of pyroclastic flows and surges by hot-rock avalanches from the dome of Mount St. Helens volcano, USA, Bull. Volcanol., 50, 14-25, 1988.

Minakami, T., On the distribution of volcanic ejecta (Part I). The distributions of volcanic bombs ejected by the recent explosions of Asama, Bull. Earthq. Res. Inst. Univ. Tokyo, 20, 65-91, 1942.

Morrissey, M. M. and L. G. Mastin, Vulcanian eruptions, in Encyclopedia of Volcanoes, edited by H. Sigurdsson, 463-476, Academic Press, San Diego, 2000.

Nairn, I. A., Atmospheric shock waves and condensation clouds from Ngauruhoe explosive eruptions, Nature, 259, 190-192, 1976.

Nairn, I. A. and S. Self, Explosive eruptions and pyroclastic avalanches from Ngauruhoe in February 1975, J. Volcanol. Geotherm. Res., 3, 39$60,1978$.

Nakada, S., M. Nagai, T. Kaneko, Y. Suzuki, and F. Maeno, The outline of the 2011 eruption at Shinmoe-dake (Kirishima), Japan, Earth Planets Space, 65, this issue, 475-488, doi:10.5047/eps.2013.03.016, 2013.

Ohba, T., H. Taniguchi, H. Oshima, M. Yoshida, and A. Goto, Effect of explosion energy and depth on the nature of explosion cloud: A field experimental study, J. Volcanol. Geotherm. Res., 115, 33-42, 2002.

Parfitt, E. A. and L. Wilson, Fundamentals of Physical Volcanology, pp. 230, Blackwell Science Ltd., 2008.

Robertson, R., P. Cole, R. S. J. Sparks, C. Harford, A. M. Lejeune, W. J. McGuire, A. D. Miller, M. D. Murphy, G. Norton, N. F. Stevens, and S. R. Young, The explosive eruption of Soufriere Hills Volcano, Montserrat, West Indies, 17 September, 1996, Geophys. Res. Lett., 25, 3429-3432, 1998

Romano, C., J. Mungall, T. Sharp, and D. B. Dingwell, Tensile strength of hydrous vesicular glasses: An experimental study, Am. Mineral., 81, 1148-1154, 1996.

Sato, H., T. Fujii, and S. Nakada, Crumbling of dacite dome lava and generation of pyroclastic flows at Unzen volcano, Nature, 360, 664666, 1992.

Self, S., L. Wilson, and I. A. Nairn, Vulcanian eruption mechanisms, Nature, 277, 440-443, 1979.

Shimbori, T. and K. Fukui, Time variation of the eruption cloud echo height from Shinmoe-dake volcano in 2011 observed by Tanegashima and Fukuoka weather radars, Rep. Coord. Comm. Predict. Volcan. Erup., 108, 2012 (in Japanese).

Spieler, O., B. Kennedy, U. Kueppers, D. B. Dingwell, B. Scheu, and J. Taddeucci, The fragmentation threshold of pyroclastc rock, Earth Planet. Sci. Lett., 226, 139-148, 2004.

Steinberg, G. S. and J. I. Babenko, Experimental velocity and density determination of volcanic gases during eruption, J. Volcanol. Geotherm. 
Res., 3, 89-98, 1978.

Stix, J., R. C. Torres, M. L. Narvaez, G. P. Cortes, J. A. Raigosa, D. M. Gomez, and R. Castonguay, A model of vulcanian eruptions at Galeras volcano, Colombia, J. Volcanol. Geotherm. Res., 77, 285-303, 1997.

Suzuki, Y., A. Yasuda, N. Hokanishi, T. Kaneko, S. Nakada, and T. Fujii, Syneruptive deep magma transfer and shallow magma remobilization during the 2011 eruption of Shinmoe-dake, Japan: Constraints from melt inclusions and phase equilibria experiments, J. Volcanol. Geotherm. Res., 257, 184-204, 2013a.

Suzuki, Y., M. Nagai, F. Maeno, A. Yasuda, N. Hokanishi, T. Shimano, M. Ichihara, T. Kaneko, and S. Nakada, Precursory activity and evolution of the 2011 eruption of Shinmoe-dake in Kirishima volcanoinsights from ash samples, Earth Planets Space, 65, this issue, 591-607, doi:10.5047/eps.2013.02.004, 2013b.

Tait, S. R., C. Jaupart, and S. Vergniolle, Pressure, gas content and eruption periodicity of a shallow, crystallizing magma chamber, Earth Planet. Sci. Lett., 92, 107-123, 1989.

Wilson, L., Relationships between pressure, volatile content and ejecta velocity in three types of volcanic explosion, J. Volcanol. Geotherm. Res., 8, 297-313, 1980.

Woods, A. W., A model of vulcanian explosions, Nucl. Eng. Design, 155, 345-357, 1995.

Yokoo, A., F. Maeno, and H. Taniguchi, Asama explosion of September 1st, 2004-On the damage to glass windows and estimation of explosion energy, Bull. Volcanol. Soc. Jpn., 50, 195-201, 2005 (in Japanese with English abstract).

F. Maeno (e-mail: fmaeno@eri.u-tokyo.ac.jp), S. Nakada, M. Nagai, and T. Kozono 